\title{
Posted Prices and Bid Affiliation: Evidence from Experimental Auctions
}

\section{Jay R. Corrigan and Matthew C. Rousu}

Abstract: In most experimental auctions, researchers ask participants to bid on the same item in multiple potentially binding rounds, posting the price submitted by the top bidder or bidders after each of those rounds. If bids submitted in later rounds are affiliated with posted prices from earlier rounds, this practice could result in biased value estimates. In this article we discuss the results of an experiment designed explicitly to test whether posted prices affect bidding behavior. We find that for familiar items, high posted prices lead to increased bids in subsequent rounds. Our results have implications for researchers conducting experimental auctions.

Keywords: Experimental Auctions, Posted Prices, Affiliation

Running Head: Posted Prices and Bid Affiliation

Jay Corrigan is assistant professor, Department of Economics, Kenyon College, and was a visiting collaborator at the Center for Agricultural and Rural Development while conducting part of this research. Matthew Rousu is assistant professor, Department of Economics, Susquehanna University. The authors thank two anonymous reviewers and seminar participants at Appalachian State University, Susquehanna University, and the University of Akron for helpful comments; Charlie Chern, Dan Phaneuf, and Jonathon Phillips, and Walter Wessels for help conducting the experiments; and Jason Shogren, John List, and Glenn Harrison for help with issues regarding data availability. These individuals are not responsible for any shortcomings of this paper. 
Experimental auctions have become a popular tool in many branches of economics, including agricultural, environmental, and regulatory economics. Economists have used experimental auctions to examine issues such as the willingness-to-pay/willingness-toaccept disparity (e.g., Kahneman, Knetsch, and Thaler 1990; Shogren et al. 1994; Shogren et al. 2001), the value of information regarding food products (e.g., Huffman et al. 2003; Rousu et al. 2002, 2004), and pricing in electricity markets (e.g., Abbink, Brandts, and McDaniel 2003). Repeated trials are now a standard practice in experimental auctions. In repeated trial auctions participants place bids on the same products in multiple potentially binding rounds, and the experimenter posts one or more of the bid prices after each round. ${ }^{1}$

In this article we take a fresh look at whether posted prices affect bids in later rounds. This article advances the literature in several important ways. First, we report the design and results of the only study designed specifically to control for the effects of posted prices on bids in subsequent rounds. We do this with the aid of confederate bidders who were instructed to bid within a certain narrow range. Thus, we have multiple treatments that vary only by the presence or absence of confederate bidders, allowing for what we believe to be the cleanest possible test of the effect of posted prices on bidding behavior in later rounds. While List and Shogren (1999) model bids in round $t$ as a function of the posted price in round $t-1$, through our use of confederate bidders to control posted prices we are able to test whether exposure to high posted prices has an effect that accumulates over the course of multiple rounds, leading to a gradual increase in mean bids. 
Second, our methods of analysis are more complete than previous work examining bid affiliation. We not only compare summary statistics from early and late rounds, but we also use panel data analysis to understand how individual participants' bids are affected by the presence of confederate bidders. Focusing on individuals rather than summary statistics allows us to understand how individual-specific characteristics influence affiliation, and it also allows us to better understand the role of outliers.

Finally, we look at whether there is a method researchers can use ex ante to mitigate the effect of aberrant posted prices on other participants' bids in subsequent rounds. Given the current ubiquity of repeated trials, this research has important implications for the rapidly expanding body of research using experimental auctions.

\section{Posted Prices, Repeated Trials, Affiliation, and Experimental Auction Valuation}

There are arguments both in favor of and against repeated trial auctions. Among the arguments in favor of repeated trials is that the practice allows participants to learn about the auction format and to form values in a market-like setting. Many believe this improves the accuracy of value estimates, e.g., Alfnes and Rickertsen 2003; Hayes et al. 1995, Lusk et al. 2001; Shogren et al. 1994; Shogren et al. 2001. While the practice of using repeated trials is widespread, not all experimental economists endorse this method (e.g., Rousu et al. 2004). Knetsch, Tang, and Thaler (2001) find that bids in a repeatedtrial auction are influenced by the choice of auction mechanism. Specifically, they show that WTP bids submitted in the later rounds of a repeated second-price auction are significantly higher than those submitted in the later rounds of a repeated ninth-price 
auction. Shogren et al. (2001) report that mean WTP bids increase in a repeated secondprice auction, but not in a repeated BDM auction where the market feedback provides no information about the upper support of the value distribution.

We believe these inconsistencies may be driven by bid affiliation. In this article we draw a distinction between bid affiliation where a high bid submitted by one participant may lead other participants to submit higher bids in later rounds (List and Shogren), and value affiliation where "a higher value of the item for one bidder makes higher values for other bidders more likely" (Kagel 1995, p. 517). ${ }^{2}$ Bid affiliation is a broader concept than value affiliation because, as we will discuss, positive correlation between bids may or may not be caused by positive correlation between values. And given that researchers are only able to observe participants' bids, bid affiliation is also more relevant to applied experimental auction studies.

There are many possible reasons for bid affiliation in an auction for goods with homegrown values. First, participants may be unfamiliar with a product and therefore uncertain of the value they would derive from it. They may, however, suspect other participants are better informed, in which case posted prices may provide more information about the product. Second, even if the participants are certain of the value they place on a product, they may be uncertain of the price the good can be purchased for outside of the experimental auction market. In this situation, posted prices may provide these participants with valuable feedback, assuming they believe that other participants have better information about the outside price (Kolstad and Guzman 1999). Third, bidders might derive utility from winning for winning's sake (Shogren and Hayes 1997). 
In the presence of a "top-dog effect," high posted prices would cause participants who derive utility from being declared the winner to submit higher bids. Fourth, if participants observe posted prices significantly higher than their own bids, they may feel they have no chance of winning the auction. This would essentially turn the experiment into a hypothetical auction, and there is a sizeable literature showing that participants in hypothetical valuation exercises submit significantly higher bids (e.g., Fox et al. 1998; Cummings and Taylor 1999; List 2001). Fifth, posted prices may provide feedback regarding the credibility of the auction market itself. If, for example, participants are skeptical of the quality of the goods being auctioned off relative to outside substitutes, or are skeptical about whether the good will actually be delivered, high posted prices may signal that other participants are confident in the auction market, thereby boosting the skeptical bidders' confidence. Finally, participants might be influenced by a behavioral "anchoring effect," where their bids tend to gravitate toward the posted price (Nunes and Boatwright 2004).

Kagel, Harstad, and Levin (1987) find no evidence of bid affiliation in induced value auctions. Using auctions for products with homegrown values, List and Shogren (1999) find that posted prices affected median bids for unfamiliar products, but not for familiar products. The authors conclude that any effect of affiliation on median bids is small. However, their analysis focuses solely on median WTP bids from each group of participants. This is in contrast with the empirical literature, which has focused almost exclusively on either mean WTP estimates (e.g., Shogren et al. 1994; Knetsch, Tang, and 
Thaler), or on tests that use individual participants' bids in a regression or other conditional analysis (e.g., Lusk et al. 2001).

The idea that posted prices may affect WTP is not restricted to laboratory auctions. Nunes and Boatwright find that bid affiliation occurs in field auctions as well. For example, in one of their experiments participants submiting bids for a music $\mathrm{CD}$ were differentiated by their passive exposure to the price posted for an unrelated product (a sweatshirt) by a nearby confederate vendor. The price of the unrelated good, which the authors refer to as an "incidental price," presumably should have no impact on participants' WTP for the CD. However, Nunes and Boatwright find that increasing the posted price of the sweatshirt from $\$ 10$ to $\$ 80$ increases the mean bid for the CD from $\$ 7.29$ to $\$ 9.00$. Similarly, the authors find that incidental prices have a positive and significant effect on WTP bids in a non-experimental English auction for classic automobiles. In particular, focusing on pairs of unrelated cars up for auction one after the other, they find that the premium the winning bidder pays for the second car relative to its list price is positively correlated with the winning bid for first car.

Taken as a whole, Nunes and Boatwright's study provides compelling evidence that seemingly irrelevant prices affect bidders' decisions, yet experimental auction practitioners continue to debate this issue. We think this is due largely to there having been no experimental auction studies specifically designed to test for bid affiliation. In the next section we discuss the design of just such an experiment. 


\section{Experimental Design}

To address our research questions, we held experimental auction sessions with 101 undergraduate economics students at three institutions: Kenyon College, North Carolina State University (NC State), and The Ohio State University (OSU). All participants were paid $\$ 10$ for taking part in the study. The participants bid on one standard-size (1.55 ounce) Hershey's candy bar and one university-logo coffee mug. At the time the auctions were conducted, an identical candy bar could be purchased at nearby shops for about $\$ 0.65$. All three coffee mugs were bought at the institutions' respective campus bookstores, where the Kenyon mug cost $\$ 3.95$, the NC State mug cost $\$ 4.65$, and the OSU mug cost \$3.99. We chose to sell a candy bar and a coffee mug because these products have been used in many experimental auction studies. In addition, in the case of the candy bar, participants were likely familiar with both the good and its price outside of the experimental auction. In the case of the coffee mug, on the other hand, while participants were familiar with the good, they were likely uncertain of the specific mug's outside price. For example, at the time this study was conducted, the Kenyon College bookstore offered 27 different coffee mugs ranging in price from $\$ 3.33$ to $\$ 14.62$. We believe this distinction is important. Of the six explanations for bid affiliation discussed above, all but the first might apply to familiar goods like coffee mugs and candy bars. Of the remaining five explanations, the most orthodox is that bid affiliation is more likely to occur if bidders are uncertain of a good's outside price but they believe their fellow participants may have better information about that price. With that in mind, the fact that 
we find that bids are affiliated for both familiar goods with unfamiliar outside prices and familiar goods with familiar outside prices is all the more striking.

We began by providing participants with both written and oral instructions on the second-price, sealed-bid auction mechanism (Vickrey 1961), followed by a short quiz to ensure their understanding. ${ }^{3}$ All participants then took part in ten rounds of bidding on a candy bar and ten rounds of bidding on a coffee mug. Similar to other studies, only one round from each set of ten was chosen to be binding (or valid) so participants would not have to worry about winning multiple units of any product. After each round, the two highest bids were posted at the front of the room along with the bidders' ID numbers. By identifying the top two bids along with the ID numbers of those bidders, participants could uniquely (yet anonymously) identify the auction winner and the participant whose bid determined the market price. After each set of rounds, the monitor randomly determined the binding round and announced the winner's ID number. Transactions were executed at the end of the experiment. ${ }^{4}$

In order to provide the cleanest possible test of the effect of posted prices, we introduced two confederate bidders into some of the treatments. (The makeup of our sessions is described in table 1.) These confederates were instructed in advance to place specific bids for the products. In the coffee mug rounds we instructed one confederate to bid between $\$ 8.60$ and $\$ 8.70$ and we instructed the other to bid between $\$ 9.20$ and $\$ 9.30$. In the candy bar rounds we asked one confederate to bid between $\$ 1.60$ and $\$ 1.70$ and the other to bid between $\$ 1.80$ and $\$ 1.90$. The confederate bidders were allowed to vary 
their bids within these ranges across rounds. The use of confederate bidders gives us much more control over posted prices relative to previous studies.

We use these experimental auctions to examine three research questions. In experiment 1 we look at how posted prices affect bids for a familiar product with a less familiar price. In this experiment our treatment and control groups differ based on the presence or absence of confederate bidders in the coffee mug rounds only. In experiment 2 we look at how posted prices affect bids for a familiar product with a more familiar price. In this experiment our treatment and control groups differ based on the presence or absence of confederate bidders in the candy bar rounds. In experiment 3 we look at whether the effects of posted prices can be mitigated if participants are repeatedly exposed to confederates. In particular, we test whether participants initially exposed to confederates in the candy bar rounds will also be affected by high posted prices in the coffee mug rounds.

\section{Experiment 1: How do posted prices affect bids for a familiar product with a less familiar market price?}

Twenty-eight participants from sessions A and B took part in the control treatment. These participants were never exposed to confederate bidders. Thirty-six participants from sessions $\mathrm{C}, \mathrm{D}$, and $\mathrm{E}$ took part in the confederate treatment. These participants were only exposed to confederate bidders in the coffee mug rounds.

Descriptive statistics from all ten rounds are shown in table 2, and the mean bids from each of the ten rounds for both the control and confederate treatments are plotted in 
figure $1 .^{5}$ Notice that the mean bids increased over time in both treatments, but that the increase was much more dramatic in the confederate treatment. ${ }^{6}$

For a tighter focus on the effect of confederate bidders on bidding behavior, we examine the bids from rounds 1 and 9 more closely. Descriptive statistics from rounds 1 and 9 are presented in table 3 . It is worth noting that in two of the confederate units, the second confederate was outbid in round 9 by a participant whose bid increased several dollars between rounds 1 and 9. The mean bids for the coffee mug increased in both the confederate and control treatments, but the increase was more than $200 \%$ greater in the confederate treatment. This $\$ 0.95$ difference in the increase in mean bids across the experimental and control treatments is statistically significant at the 0.02 level in a onesided $t$-test. ${ }^{7}$ While the difference in mean bids reveals a large posted-price effect, median bids do not differ as dramatically across the treatments. A Wilcoxon rank-sum test, which can be thought of as comparing differences in medians instead of means, shows that the difference is not statistically significant $(p=0.30)$. This is consistent with List and Shogren's finding that the median bid for familiar goods increases across rounds but is not significantly impacted by posted prices.

Figure 2 plots participants' round 1 bids against the change in their bids between rounds 1 and 9. Understanding the distribution of bid increases depicted in this figure is key to understanding how our results relate to List and Shogren's. The figure shows that the increase in bids across rounds in the confederate treatment, though positively skewed, is clearly greater than that in the control treatment and that this difference is not solely driven by a small group of extreme outliers. This result underscores the importance of 
focusing on more than one moment of the distribution when making inferences in experimental auctions. Figure 2 also shows that high posted prices can cause bidders at any point in the value distribution to increase their bids. Normal correlation analysis (Freund 1992) shows that there is no statistically significant correlation between round 1 bids and change in bids between rounds 1 and $9(p=0.33)$.

In order to account for the panel nature of our data, we use random-effects regression analysis to estimate individuals' bids as

$$
B i d_{i t}=\alpha_{i}+\tau T+\gamma\left(C_{i} \times T\right)+\varepsilon_{i t},
$$

where $B_{i t}$ is participant $i$ 's bid in round $t, \alpha_{i}$ is a random-effects intercept term, $T$ is a time trend, $C_{i}$ is a dummy variable equal to one if individual $i$ is bidding in the confederate treatment, and $\varepsilon_{i t}$ is a contemporaneous error term. This specification allows us test whether individuals' bids increase more rapidly in the confederate treatment. We believe that this specification is superior to estimating bids submitted in round $t$ as a function of the posted price in round $t-1$ because it allows for the effects of high posted prices to "accumulate" over more than one round.

Column 1 of table 4 presents the random-effects estimation results for equation (1). The coefficient associated with the time trend $T$ is positive but only marginally significant $(p=0.08)$. The coefficient associated with the cross term $\left(C_{i} \times T\right)$ is positive and highly significant $(p<0.01)$, indicating that individuals' bids increase significantly more across rounds in the presence of confederate bidders. Specifically, bids submitted by participants in the confederate treatment increased, on average, by $\$ 0.104$ more per 
round than did the bids of participants in the control treatment. This result underscores the importance of our confederate-bidder design, in that it shows that the observed increase in mean bids in the confederate treatment is not simply due to repeated bidding, but is the result of persistently high posted prices.

To better understand if participants' individual characteristics are driving bid affiliation, we also use random-effects analysis to estimate individuals' bids as

$$
\operatorname{Bid}_{i t}=\alpha_{i}+\beta^{\prime} \boldsymbol{X}_{i}+\tau T+\gamma\left(C_{i} \times T\right)+\varphi\left(\boldsymbol{X}_{i} \times C_{i} \times T\right)+\varepsilon_{i t},
$$

where $\boldsymbol{X}_{i}$ is a vector including participants' gender, mean-deleted monthly disposable income (in hundreds of dollars), and mean-deleted cumulative grade point average (GPA). ${ }^{8}$ Column 2 of table 4 presents the estimation results for equation (2). The coefficient associated with the time trend $T$ is once again positive but only marginally significant $(p=0.07)$. And while none of the socioeconomic intercept terms are significantly different from zero, both gender and GPA have a positive and highly significant effect on the rate at which bids increase in the confederate treatment $(p<0.01$ for both coefficients). In particular, the gender coefficient suggests that in the confederate treatment, male participants' bids increased more rapidly than females' by an average of $\$ 0.113$ per round, perhaps suggesting that men are more driven to be declared the winner of an auction. Similarly, in the confederate treatment a one-tenth-point increase in GPA corresponds to a $\$ 0.025$ per-round increase in bids. While it may initially seem surprising that better students are more likely to be "fooled" by confederate bidders, this result may suggest that the more studious participants are the ones most likely to realize that even a private-value good has a common-value component when 
there is uncertainty surrounding the good's outside price (Kolstad and Guzman). As we will show in the next section, the correlation between GPA and increasing bids disappears when participants bid on a good with a more familiar market price.

Most strikingly, though, the coefficient associated with $\left(C_{i} \times T\right)$ is no longer significantly different from zero $(p=0.27)$, indicating that female students with average GPAs are not affected by high posted prices. In sum, these results suggest that the difference in bidding behavior between the control and confederate treatments is driven by men and above-average students.

\section{Experiment 2: How do posted prices affect bids for a familiar product with a more familiar market price?}

For experiment 2, we used the same procedures as in experiment 1. Sixty-four participants from sessions A through E took part in the control treatment, while thirtyseven participants from sessions $\mathrm{F}$ and $\mathrm{G}$ took part in the confederate treatment. This experiment is of interest because candy bars of similar sizes generally have prices that are fairly consistent across stores and across brands. Since participants likely entered this experiment familiar with both the candy bar for sale and its outside market price, any bid affiliation cannot simply be attributed to participants using posted prices as a signal of the good's outside price. Bid affiliation in this experiment must instead be attributed to less conventional explanations such as anchoring or top-dog effects.

Table 5 shows the descriptive statistics for bidding on the candy bar in all ten rounds for each treatment. Figure 3 shows the mean bid across rounds for both the 
control and confederate treatments. In the control treatment there is very little change in the mean bid across rounds. In the confederate treatment, however, the mean bid more than doubles between rounds 1 and 9 .

Table 6 focuses more carefully on the difference between rounds 1 and 9 . Notice that while in the control treatment there is no change in mean bids, in the confederate treatment there is a $\$ 0.34$ increase. This difference in the overall increase in mean bids between the control and confederate treatments is statistically significant using a onesided $t$-test $(p<0.01) .{ }^{9}$ Similarly, the difference in median bids is statistically significant using a one-sided Wilcoxon rank-sum test $(p=0.02)$. This contrasts with List and Shogren, who found that posted prices did not affect median bids for familiar items. ${ }^{10}$

Figure 4 plots participants' round 1 bids against the change in their bids between rounds 1 and 9. As in experiment 1, the figure shows that our results are not being driven by a few extreme outliers. In this experiment both mean and median bids increased significantly despite the fact that candy bars have a relatively familiar market price. This increase in bids, despite the familiarity of the good and its outside price, suggests that the bid affiliation observed in this experiment is driven less by perceptions that posted prices contain meaningful market information than it is by alternative explanations such as a top-dog effect or by the anchoring effect of incidental prices. Figure 4 also shows that large bid increases are not limited to either high or low bidders in the confederate treatment. Normal correlation analysis again shows that there is no statistically significant correlation between round 1 bids and change in bids between rounds 1 and 9 in the confederate treatment $(p=0.20)$. 
To better understand the impact of high posted prices on individuals' candy bar bids we use random-effects regression analysis as in equations (1) and (2). Column 1 of table 7 presents the random-effects estimation results for equation (1). As in experiment 1, the coefficient associated with the cross term $\left(C_{i} \times T\right)$ is positive and highly significant $(p<0.01)$, again indicating that individuals' bids increase significantly more across rounds in the presence of confederate bidders. Specifically, bids submitted by participants in the confederate treatment increased, on average, by $\$ 0.025$ more per round than did the bids of participants in the control treatment.

But column 2 shows that understanding the role of socioeconomic characteristics is key to understanding bid affiliation. Similar to the results from experiment 1 , we again find that male participants are significantly more likely to increase their bids when exposed to high posted prices $(p=0.03)$, this time by an average of $\$ 0.023$ per round, and that the coefficient associated with $\left(C_{i} \times T\right)$ is not significantly different from zero $(p=0.31)$. Here, income has a statistically significant impact on both starting bids and the degree to which bids increase across rounds in the presence of confederates $(p<0.01$ in both cases). However, while higher-income participants are likely to submit significantly higher opening bid, they are significantly less likely to increase their bids across rounds in the confederate treatment. 


\section{Experiment 3: How does repeated exposure affect the bias from posted prices?}

Our results show that high posted prices can increase bids for familiar products in a repeated trial auction both on average and in certain demographic subgroups. It would be helpful to find a method that could mitigate this bias ex ante. To explore this possibility, we examine the coffee mug bids submitted by participants who were first exposed to confederate bidders in the candy bar rounds and were then exposed to the same confederate bidders in the coffee mug rounds. Twenty-eight participants from sessions A and B took part in the control treatment where they were never exposed to confederate bidders. Thirty-six participants from sessions $\mathrm{C}, \mathrm{D}$, and $\mathrm{E}$ took part in the confederate treatment where they were only exposed to confederate bidders in the coffee mug rounds. Thirty-seven students from sessions F and G took part in the "double confederate treatment" where they were exposed to confederate bidders in both the candy bar and coffee mug rounds.

Figure 5 shows the mean bids across rounds from the control and confederate treatments described under experiment 1 , and from the double confederate treatment. Table 8 presents summary statistics from the control, confederate, and double confederate treatments. Two points are worth noting. First, bids from round 1 in the double confederate treatment are higher than bids from round 1 in the confederate treatment. This is consistent with Nunes and Boatwright's finding that bids are influenced by posted prices for an unrelated product, and it suggests that participants who are exposed to high posted prices in a series of warm-up rounds for an unrelated product may subsequently be expected to submit higher bids. However, the difference in round 1 bids between the 
control and double confederate treatments is not statistically significant using either a one-sided t-test or Wilcoxon rank-sum test ( $p=0.23$ and 0.35 , respectively). Second, mean bids from the double confederate treatment increase only modestly across rounds.

Table 9 presents the change in mean and median coffee mug bids between rounds 1 and 9 in the control, confederate, and double confederate treatments We cannot reject the null hypothesis that mean bids increased by the same amount across rounds in the control and double confederate treatments $(p=0.39$ in a one-sided $t$ test). Results from a Wilcoxon rank-sum test were similar ( $p=0.19$ in a one-sided test). This suggests that while high posted prices may lead to increased mean bids for one product, affiliation wanes when participants see that the same bidders submit unusually high bids for a second product. Figure 6 shows no clear relationship between the increase in bids across rounds 1 and 9 and whether participants were exposed to confederates. Table 10 reports the results of a random-effects analysis, showing that only the intercept term and the coefficient associated with the time trend are significantly different from zero. In particular, gender has no impact on bidding behavior when participants have previously been exposed to confederate bidders.

\section{Discussion and Implications}

In the absence of affiliation, high posted prices should have no impact on the bids participants submit in later rounds. If this is the case, researchers are correct in arguing that repeated trials provide important market feedback, thereby providing more reliable value estimates (see Lusk 2003 for a discussion). However, to date, no experiment has 
been specifically designed to examine this issue. Given the ubiquity of repeated-trial experimental auctions, this represents a major gap in the literature.

In this article we show that posted prices have a statistically and economically significant impact on bids submitted in subsequent rounds. This is a key finding, as researchers who use repeated trials typically use bids from later rounds in their statistical analysis. And since the goods for sale in our experiment were familiar ones, our results suggest that quality or outside-price information derived from posted prices are not the primary factors driving bid affiliation. Further, we find that the propensity to increase bids is not dependent on a participant's initial bid-participants throughout the value distribution increase their bids. We also find that men are more likely than women to increase their bids when facing high posted prices, perhaps suggesting that men are more driven to win for winning's sake.

One possible criticism of our study is that posted prices in confederate treatments were so high as to effectively turn all bidders into off-margin bidders. If the explanation to bid affiliation lies primarily in off-margin bidders inflating their bids, our results may not generalize to auction with less extreme outliers. It is, however, unlikely that offmargin detachment alone is driving our results. For example, this detachment explanation conflicts with the results from experiment 3 , where we find that participants exposed to high posted prices in both the candy bar and coffee mug rounds did not increase their bids the second time they were exposed. And if off-margin detachment was a primary factor driving bid affiliation in our experiments, we would expect the offmargin effect to be greatest among bidders at the bottom of the value distribution. But as 
we have discussed, there was no significant correlation between first round bids in the confederate treatments and the increase in bids between rounds 1 and 9 .

If researchers insist on using repeated-trial Vickrey auctions, our results suggest that while participants can be influenced by aberrant bidders in one set of rounds, they appear to realize that these bidders have unrealistic valuations when the next item is auctioned off. Therefore, researchers interested in "inoculating" participants against the influence of one or two bidders with unusually high valuations could run a series of warm-up auctions with posted prices and ID numbers.

However, this suggestion comes with two important qualifications. First, we cannot be sure that posting ID numbers in the warm-up rounds will guard against affiliation since our results depend on the high bidders from the auction rounds of interest being the same as those from the warm-up rounds. Second, Nunes and Boatwright find that high posted prices have a significant positive effect on WTP bids even if those posted prices are for an unrelated good.

Based on the results presented here and in other studies suggesting that posted prices may influence bids submitted in subsequent rounds, we think that researchers should abandon repeated-trial Vickrey auctions. Instead, to avoid bid affiliation we suggest that researchers use just one round of bidding for any given good or bundle of goods. This could be accomplished by instructing participants to submit bids for different goods in distinct potentially-binding auction rounds either simultaneously (e.g., Corrigan and Rousu 2006a; Rousu et al. 2005) or sequentially but without posting prices between rounds (e.g., Noussair, Robin, and Ruffieux). For example, Rousu et al. (2004) 
instruct participants to submit bids for both conventional and genetically-modified food products in two sequential auction rounds without posting prices. While bids in both auction rounds may be affected by posted prices for the unrelated goods sold in the introductory practice auctions, taking the difference between bids for the conventional and GM products should mitigate this bias.

With repeated-trial Vickrey auctions, the risk that high bids submitted by one or two auction participants may somehow bias value estimates is simply too great. This is especially true considering that it is now standard practice for auction monitors to present participants with both written and oral explanations of the auction mechanism, to administer a quiz on the format of the auction, and then to conduct one or more practice auctions. Given such a thorough introduction, additional market feedback via repeated trials seems unnecessary. Further, the demand-revealing properties of Vickrey auctions require that bidders' valuations be independent. If bids are affiliated, the demandrevealing nature of Vickrey auctions breaks down (Milgrom and Weber 1982). 


\section{Footnotes}

${ }^{1}$ A non-comprehensive list of studies that use repeated trials includes Alfnes and Rickertsen (2003); Buhr et al. (1993); Dickinson and Bailey (2002); Fox (1995); Fox et al. (1994); Fox et al. (1995); Fox, Hayes, and Shogren (2002); Hayes et al. (1995); Lusk et al. (2001); Lusk et al. (2004); Shogren et al. (1994); and Shogren, List, and Hayes(2000).

${ }^{2}$ Value affiliation is often discussed in relation to auctions for common-value goods such as off-shore drilling rights.

${ }^{3}$ While there are many demand-revealing auction mechanisms (e.g., the random nth-price and Becker-DeGroot-Marschak auctions), we chose to use the second-price auction because of its overwhelming popularity in repeated-trial auction studies. For example, List and Shogren (1999) use data from more than 40 repeated-trial second-price auction experiments.

${ }^{4}$ The instructions given to auction participants are available in Corrigan and Rousu (2006b).

${ }^{5}$ Our confederate bidders did not bid their true value, but the values we asked them to bid. Therefore, their bids are excluded from all of our statistical analyses.

${ }^{6}$ The increase in bids in the control group is consistent with List and Shogren's finding that bids tend to increase in repeated-trial Vickrey auctions. There is evidence that different auction mechanisms might yield different results. For example, Shogren et al. (2001) find that mean WTP bids increase across rounds in a second-price auction but not 
in a BDM auction. Lusk, Alexander, and Rousu (2004) show that the BDM, random nthprice, and second-price auction mechanisms provide different incentives for participants to remain truthful and Lusk and Rousu (in press) support this result empirically.

${ }^{7}$ We chose to focus our analysis on round 9 instead of round 10 because of evidence that participants often behave unusually in the last round of an experiment (Friedman and Sunder 1994). However, to make sure that our findings are not driven by unusual results from one particular round, we ran the same test comparing the mean bids from rounds 1 through 3 with those from rounds 8 through 10, and found results that were qualitatively similar $(p=0.04$ in a one-sided $t$-test). We also repeated these tests after excluding zero bidders, and again found qualitatively similar results ( $p=0.03$ in a one-sided $t$-test comparing rounds 1 and 9 , and $p=0.05$ in a one-sided $t$-test comparing rounds 1 through 3 and 8 through 10). These and all other non-published results are available in Corrigan and Rousu (2006b).

${ }^{8}$ Here and in equation (1) we allow for idiosyncratic effects to influence the intercept (i.e., participant $i$ 's bid in round 1) but not the time trend coefficient $\tau$ (i.e., the roundon-round increase in bids in the absence of confederates). We have chosen this specification because while it is obvious that unmodeled, individual-specific characteristics like a participant's fondness for coffee may influence her initial bid for a coffee mug, it is not obvious why these unmodeled characteristics would influence changes in bidding behavior across rounds.

${ }^{9}$ Again, results are qualitatively similar comparing mean bids from rounds 1 through 3 with those from rounds 8 through 10 , or if zero bidders are excluded. 
${ }^{10}$ As mentioned earlier, an identical candy bar could be purchased outside of the experiment at nearby shops for about $\$ 0.65$. In the control treatment, nine out of 64 participants submitted bids greater than this $\$ 0.65$ outside price in round 1 , versus 13 out of 64 in round 9. A chi-square test of independence fails to reject the null hypothesis that these two frequencies are equal $(p=0.35)$. In the confederate treatment, three out of 37 participants submitted bids greater than the outside price in round 1, versus 13 out of 37 in round 9. In this case, a chi-square test of independence rejects the null hypothesis that these two frequencies are equal $(p<0.01)$, suggesting that confederates were capable of prompting some participants to submit bids greater than the outside price of a perfect substitute. 


\section{References}

Abbink, K., J. Brandts, T. McDaniel. 2003. "Asymmetric Demand Information in Uniform and Discriminatory Call Auctions: An Experimental Analysis Motivated by Electricity Markets.” Journal of Regulatory Economics 23:125-44.

Alfnes, F., K. Rickertsen. 2003. “European Consumers' Willingness to Pay for U.S. Beef in Experimental Auction Markets." American Journal of Agricultural Economics 85:396-405.

Buhr, B., D. Hayes, J. Shogren, J. Kliebenstein. 1993. "Valuing Ambiguity: The Case of Genetically Engineered Growth Enhancers." Journal of Agricultural and Resource Economics 18:175-84.

Corrigan, J., M. Rousu. 2006a. “The Effect of Initial Endowments in Experimental Auctions." American Journal of Agricultural Economics 88:in press.

Corrigan, J., M. Rousu. 2006b. “AJAE Appendix: Posted Prices and Bid Affiliation: Evidence from Experimental Auctions." Unpublished manuscript. Available at: http://agecon.lib.umn.edu/.

Cummings, R., L. Taylor. 1999. "Unbiased Value Estimates for Environmental Goods: A Cheap Talk Design for the Contingent Valuation Method.” American Economic Review 89:649-65.

Dickinson, D., D. Bailey. 2002. "Meat Traceability: Are U.S. Consumers Willing to Pay for It?" Journal of Agricultural and Resource Economics 27:348-64.

Fox, J. 1995. "Determinants of Consumer Acceptability of Bovine Somatotropin." Review of Agricultural Economics 17:51-62. 
Fox, J., B. Buhr, J. Shogren, J. Kliebenstein, D. Hayes. 1995. “A Comparison of Preferences for Pork Sandwiches Produced from Animals With and Without Somatotropin Administration.” Journal of Animal Science 73:1048-54.

Fox, J., D. Hayes, J. Kliebenstein, J. Shogren. 1994. “Consumer Acceptability of Milk from Cows Treated with Bovine Somatotropin.” Journal of Dairy Science 77:703-07.

Fox, J., D. Hayes, J. Shogren. 2002. “Consumer Preferences for Food Irradiation: How Favorable and Unfavorable Descriptions Affect Preferences for Irradiated Pork in Experimental Auctions.” Journal of Risk and Uncertainty 24:75-95.

Fox, J., J. Shogren, D. Hayes, J. Kliebenstein. 1998. “CVM-X: Calibrating Contingent Values with Experimental Auction Markets." American Journal of Agricultural Economics 80:455-65.

Freund, J. 1992. Mathematical Statistics. Upper Saddle River, New Jersey: Prentice Hall.

Friedman, D., S. Sunder. 1994. Experimental Methods: A Primer for Economists. Cambridge: Cambridge University Press.

Hayes, D., J. Shogren, S. Shin, J. Kliebenstein. 1995. "Valuing Food Safety in Experimental Auction Markets." American Journal of Agricultural Economics 77:4053.

Huffman, W., M. Rousu, J. Shogren, A. Tegene. 2003. “The Public Good Value of Information from Agribusinesses on Genetically Modified Foods.” American Journal of Agricultural Economics 85:1309-15. 
Kagel, J. 1995. “Auctions: A Survey of Experimental Research.” In J. Kagel and A. Roth, eds. Handbook of Experimental Economics. Princeton: Princeton University Press, pp. 501-85.

Kagel, J., R. Harstad, D. Levin. 1987. "Information Impact and Allocation Rules in Auctions with Affiliated Private Values: A Laboratory Study." Econometrica 55:1275-304.

Kahneman, D., J. Knetsch, R. Thaler. 1990. "Experimental Tests of the Endowment Effect and the Coase Theorem." Journal of Political Economy 98:1325-48.

Knetsch, J., F. Tang, R. Thaler. 2001. “The Endowment Effect and Repeated Market Trials: Is the Vickrey Auction Demand Revealing?" Experimental Economics 4:25769.

Kolstad, C., R. Guzman. 1999. "Information and the Divergence between Willingness to Accept and Willingness to Pay." Journal of Environmental Economics and Management 38:66-80.

List, J. 2001. "Do Explicit Warnings Eliminate the Hypothetical Bias in Elicitation Procedures? Evidence from Field Auctions for Sportscards." American Economic Review 91:1498-507.

List, J. and J. Shogren. 1999. "Price Information and Bidding Behavior in Repeated Second-price Auctions." American Journal of Agricultural Economics 81:942-49.

Lusk, J. 2003. "Using Experimental Auctions for Marketing Applications: A Discussion." Journal of Agricultural and Applied Economics 35:349-60. 
Lusk, J., C. Alexander, M. Rousu. 2004. "Designing Experimental Auctions for Marketing Research: The Effect of Values, Distributions, and Mechanisms on Incentives for Truthful Bidding." Working paper, Department of Economics, Susquehanna University.

Lusk, J., M. Daniel, D. Mark, C. Lusk. 2001. “Alternative Calibration and Auction Institutions for Predicting Consumer Willingness to Pay of Nongenetically Modified Corn Chips." Journal of Agricultural and Resource Economics 26:40-57.

Lusk, J., L. House, C. Valli, S. Jaeger, M. Moore, B. Morrow, W. Traill. 2004. "Effect of Information About Benefits of Biotechnology on Consumer Acceptance of Genetically Modified Food: Evidence from Experimental Auctions in the United States, England, and France." European Review of Agricultural Economics 31:179204.

Lusk, J., M. Rousu. Forthcoming. "Market Price Endogeneity and Accuracy of Value Elicitation Mechanisms." Using Experimental Methods in Environmental and Resource Economics. Edited by J. List. Cheltenham, UK: Edward Elgar Publishing. Milgrom, P., R. Weber. 1982. "A Theory of Auctions and Competitive Bidding." Econometrica 50:1089-122.

Noussair, C., S. Robin, B. Ruffieux. 2002. "Do Consumers Not Care about Biotech Foods or do they Just Not Read the Labels." Economics Letters 75:47-53.

Nunes, J., P. Boatwright. 2004. "Incidental Prices and Their Effect on Willingness to Pay." Journal of Marketing Research 16:457-66. 
Rousu, M., W. Huffman, J. Shogren, A. Tegene. 2002. “The Value of Verifiable Information in a Controversial Market: Evidence from Lab Auctions of GM foods." Working paper, Department of Economics, Susquehanna University.

—. 2004. "Estimating the Public Value of Conflicting Information: The Case of Genetically Modified Foods." Land Economics 80:125-35.

Rousu, M., D. Monchuk, J. Shogren, K. Kosa. 2005. “Consumer Perceptions of Labels and the Willingness to Pay for 'Second-Generation' Genetically Modified Products." Journal of Agricultural and Applied Economics 37: 647-57.

Shogren, J., S. Cho, C. Koo, J. List, C. Park, P. Polo, R. Wilhelmi. 2001. “Auction Mechanisms and the Measurement of WTP and WTA.” Resource and Energy Economics 23:97-109.

Shogren, J., D. Hayes. 1997. "Resolving Differences in Willingness to Pay and Willingness to Accept: Reply.” American Economic Review 87:241-44.

Shogren, J., List, J., D. Hayes. 2000. "Preference Learning in Consecutive Experimental Auctions." American Journal of Agricultural Economics 83:1016-21.

Shogren, J., S. Shin, D. Hayes, J. Kliebenstein. 1994. "Resolving Differences in Willingness to Pay and Willingness to Accept." American Economic Review 84:25570.

Vickrey, W. 1961. “Counterspeculation, Auctions, and Competitive Sealed Tenders.” Journal of Finance 16:8-37.

Wooldridge, J. 2002. Econometric Analysis of Cross Section and Panel Data. Cambridge: MIT Press. 
Table 1. Summary of Experimental Sessions

\begin{tabular}{ccccc}
\hline Session & Location & $\begin{array}{c}\text { Number of } \\
\text { participants }\end{array}$ & $\begin{array}{c}\text { Candy bar } \\
\text { confederates? }\end{array}$ & $\begin{array}{c}\text { Coffee mug } \\
\text { confederates? }\end{array}$ \\
\hline A & Kenyon & 19 & No & No \\
B & OSU & 9 & No & No \\
C & Kenyon & 10 & No & Yes \\
D & OSU & 15 & No & Yes \\
E & NC State & 11 & No & Yes \\
F & Kenyon & 16 & Yes & Yes \\
G & NC State & 21 & Yes & Yes \\
\hline
\end{tabular}


Table 2. Summary Statistics for Coffee Mug Bids in Experiment 1

\begin{tabular}{|c|c|c|c|c|c|c|c|c|}
\hline & \multicolumn{4}{|c|}{ Control treatment $(\mathrm{N}=28)$} & \multicolumn{4}{|c|}{ Confederate treatment $(\mathrm{N}=36)$} \\
\hline & Mean & Median & $\begin{array}{l}\text { Standard } \\
\text { deviation }\end{array}$ & Zero bids & Mean & Median & $\begin{array}{l}\text { Standard } \\
\text { deviation }\end{array}$ & Zero bids \\
\hline Round 1 & $\$ 1.04$ & $\$ 1.00$ & $\$ 0.86$ & $28.6 \%$ & $\$ 1.26$ & $\$ 0.72$ & $\$ 1.36$ & $11.1 \%$ \\
\hline Round 2 & $\$ 1.20$ & $\$ 1.00$ & $\$ 0.90$ & $21.4 \%$ & $\$ 1.68$ & $\$ 1.13$ & $\$ 1.56$ & $11.1 \%$ \\
\hline Round 3 & $\$ 1.34$ & $\$ 1.25$ & $\$ 0.95$ & $21.4 \%$ & $\$ 2.04$ & $\$ 1.25$ & $\$ 2.03$ & $13.9 \%$ \\
\hline Round 4 & $\$ 1.49$ & $\$ 1.31$ & $\$ 1.05$ & $21.4 \%$ & $\$ 2.07$ & $\$ 1.00$ & $\$ 2.11$ & $11.1 \%$ \\
\hline Round 5 & $\$ 1.50$ & $\$ 1.29$ & $\$ 1.21$ & $21.4 \%$ & $\$ 2.40$ & $\$ 1.00$ & $\$ 2.72$ & $11.1 \%$ \\
\hline Round 6 & $\$ 1.46$ & $\$ 1.27$ & $\$ 1.13$ & $21.4 \%$ & $\$ 2.04$ & $\$ 1.00$ & $\$ 2.53$ & $16.7 \%$ \\
\hline Round 7 & $\$ 1.49$ & $\$ 1.25$ & $\$ 1.18$ & $21.4 \%$ & $\$ 2.39$ & $\$ 1.00$ & $\$ 2.84$ & $16.7 \%$ \\
\hline Round 8 & $\$ 1.55$ & $\$ 1.28$ & $\$ 1.17$ & $28.6 \%$ & $\$ 2.56$ & $\$ 1.07$ & $\$ 3.04$ & $19.4 \%$ \\
\hline Round 9 & $\$ 1.48$ & $\$ 1.23$ & $\$ 1.15$ & $25.0 \%$ & $\$ 2.65$ & $\$ 1.00$ & $\$ 3.01$ & $16.7 \%$ \\
\hline Round 10 & $\$ 1.45$ & $\$ 1.22$ & $\$ 1.15$ & $21.4 \%$ & $\$ 2.71$ & $\$ 1.10$ & $\$ 3.11$ & $13.9 \%$ \\
\hline
\end{tabular}


Table 3. Summary Statistics for Coffee Mug Bids in Experiment 1

\begin{tabular}{cccc}
\hline & Round 1 & Round 9 & Difference \\
\cline { 2 - 4 } Control treatment $(\mathrm{N}=28)$ & $\$ 1.04$ & $\$ 1.48$ & $\$ 0.44$ \\
Mean & $\$ 1.00$ & $\$ 1.23$ & $\$ 0.23$ \\
Mean market price & $\$ 2.47$ & $\$ 2.56$ & \\
Confederate treatment $(\mathrm{N}=36)$ & & & \\
Mean & $\$ 1.26$ & $\$ 2.65$ & $\$ 1.39^{\dagger}$ \\
Median & $\$ 0.72$ & $\$ 1.00$ & $\$ 0.28$ \\
Mean market price & $\$ 8.65$ & $\$ 8.91$ & \\
\hline
\end{tabular}

${ }^{\dagger}$ Statistically different across treatments at the 0.02 level $(t=2.03)$. 
Table 4. Random-Effects Estimation Results for Coffee Mug Bids in Experiment 1 ( $\mathrm{N}=640$ )

\begin{tabular}{|c|c|c|}
\hline Variable & (1) & (2) \\
\hline Constant & $\begin{array}{c}1.309^{* *} \\
(0.000)^{\mathrm{a}}\end{array}$ & $\begin{array}{l}1.256^{* *} \\
(0.000)\end{array}$ \\
\hline Trend & $\begin{array}{c}0.038 \\
(0.083)\end{array}$ & $\begin{array}{c}0.038 \\
(0.074)\end{array}$ \\
\hline Male & - & $\begin{array}{c}0.101 \\
(0.824)\end{array}$ \\
\hline Income & - & $\begin{array}{l}-0.021 \\
(0.873)\end{array}$ \\
\hline GPA & - & $\begin{array}{l}-0.424 \\
(0.490)\end{array}$ \\
\hline Trend $\times$ Confederate & $\begin{array}{l}0.105^{* *} \\
(0.000)\end{array}$ & $\begin{array}{c}0.040 \\
(0.268)\end{array}$ \\
\hline Trend $\times$ Confederate $\times$ Male & - & $\begin{array}{l}0.114^{* *} \\
(0.003)\end{array}$ \\
\hline Trend $\times$ Confederate $\times$ Income & - & $\begin{array}{l}-0.002 \\
(0.848)\end{array}$ \\
\hline Trend $\times$ Confederate $\times$ GPA & - & $\begin{array}{l}0.253^{* *} \\
(0.000)\end{array}$ \\
\hline $\mathrm{R}^{2}$ & 0.057 & 0.079 \\
\hline
\end{tabular}

${ }^{\mathrm{a}} p$ values in parentheses.

* Significant at the 0.05 level.

** Significant at the 0.01 level. 
Table 5. Summary Statistics for the Candy Bar Bids in Experiment 2

\begin{tabular}{llccccccc}
\hline & \multicolumn{3}{c}{ Control treatment $(\mathrm{N}=64)$} & \multicolumn{3}{c}{ Confederate treatment $(\mathrm{N}=37)$} \\
\cline { 2 - 8 } & Mean & Median & $\begin{array}{c}\text { Standard } \\
\text { deviation }\end{array}$ & Zero bids & Mean & Median & $\begin{array}{c}\text { Standard } \\
\text { deviation }\end{array}$ \\
\hline Round 1 & $\$ 0.39$ & $\$ 0.25$ & $\$ 0.58$ & $29.7 \%$ & $\$ 0.28$ & $\$ 0.25$ & $\$ 0.27$ & $16.2 \%$ \\
Round 2 & $\$ 0.39$ & $\$ 0.25$ & $\$ 0.50$ & $28.1 \%$ & $\$ 0.39$ & $\$ 0.25$ & $\$ 0.54$ & $32.4 \%$ \\
Round 3 & $\$ 0.39$ & $\$ 0.32$ & $\$ 0.35$ & $26.6 \%$ & $\$ 0.47$ & $\$ 0.40$ & $\$ 0.52$ & $27.0 \%$ \\
Round 4 & $\$ 0.41$ & $\$ 0.35$ & $\$ 0.35$ & $28.1 \%$ & $\$ 0.48$ & $\$ 0.40$ & $\$ 0.49$ & $24.3 \%$ \\
Round 5 & $\$ 0.41$ & $\$ 0.40$ & $\$ 0.34$ & $29.7 \%$ & $\$ 0.53$ & $\$ 0.50$ & $\$ 0.53$ & $21.6 \%$ \\
Round 6 & $\$ 0.40$ & $\$ 0.41$ & $\$ 0.34$ & $29.7 \%$ & $\$ 0.52$ & $\$ 0.40$ & $\$ 0.60$ & $21.6 \%$ \\
Round 7 & $\$ 0.44$ & $\$ 0.45$ & $\$ 0.39$ & $26.6 \%$ & $\$ 0.54$ & $\$ 0.40$ & $\$ 0.55$ & $21.6 \%$ \\
Round 8 & $\$ 0.40$ & $\$ 0.40$ & $\$ 0.31$ & $28.1 \%$ & $\$ 0.55$ & $\$ 0.50$ & $\$ 0.57$ & $27.0 \%$ \\
Round 9 & $\$ 0.39$ & $\$ 0.40$ & $\$ 0.31$ & $25.0 \%$ & $\$ 0.62$ & $\$ 0.50$ & $\$ 0.64$ & $32.4 \%$ \\
Round 10 & $\$ 0.40$ & $\$ 0.40$ & $\$ 0.32$ & $26.6 \%$ & $\$ 0.55$ & $\$ 0.50$ & $\$ 0.55$ & $27.0 \%$ \\
\hline
\end{tabular}


Table 6. Summary Statistics for Candy Bar Bids in Experiment 2

\begin{tabular}{llll}
\hline & Round 1 & Round 9 & Difference \\
\cline { 2 - 4 } Control treatment $(\mathrm{N}=64)$ & & & \\
Mean & $\$ 0.39$ & $\$ 0.39$ & $\$ 0.00$ \\
Median & $\$ 0.25$ & $\$ 0.40$ & $\$ 0.15$ \\
Mean market price & $\$ 0.67$ & $\$ 0.70$ & \\
Confederate treatment $(\mathrm{N}=37)$ & & & \\
Mean & $\$ 0.28$ & $\$ 0.62$ & $\$ 0.34^{\dagger}$ \\
Median & $\$ 0.25$ & $\$ 0.50$ & $\$ 0.25^{\dagger \dagger}$ \\
Mean market price & $\$ 1.65$ & $\$ 1.83$ & \\
\hline
\end{tabular}

$\dagger$ Statistically different across treatments at the 0.01 level $(t=2.98)$.

iं Statistically different across treatments at the 0.02 level using a one-sided Wilcoxon rank-sum test $(z=2.21)$. 
Table 7. Random-Effects Estimation Results for the Candy Bar Bids in Experiment $2(\mathrm{~N}=1010)$

\begin{tabular}{ccc}
\hline Variable & $(1)$ & $(2)$ \\
& & $0.337^{* *}$ \\
Constant & $0.374^{* *}$ & $(0.000)$ \\
Trend & $(0.000)^{\mathrm{a}}$ & 0.002 \\
Male & 0.002 & $(0.539)$ \\
& $(0.573)$ & 0.059 \\
Income & - & $(0.413)$ \\
GPA & - & $0.066^{* *}$ \\
& & $(0.001)$ \\
Trend $\times$ Confederate & - & -0.033 \\
& & $(0.726)$ \\
Trend $\times$ Confederate $\times$ Male & $0.025^{* *}$ & 0.009 \\
Trend $\times$ Confederate $\times$ Income & $(0.000)$ & $(0.310)$ \\
Trend $\times$ Confederate $\times$ GPA & - & $0.023^{*}$ \\
$\mathrm{R}^{2}$ & - & $(0.031)$ \\
& - & $-0.014^{* *}$ \\
& & $(0.000)$ \\
& 0.019 & -0.002 \\
& & $0.871)$ \\
& & 0.066
\end{tabular}

${ }^{\mathrm{a}} p$ values in parentheses.

* Significant at the 0.05 level

** Significant at the 0.01 level. 
Table 8. Summary Statistics for Coffee Mug Bids in Experiment 3

\begin{tabular}{ccccccccc}
\hline & \multicolumn{2}{c}{$\begin{array}{c}\text { Control treatment } \\
(\mathrm{N}=28)\end{array}$} & \multicolumn{2}{c}{$\begin{array}{c}\text { Confederate treatment } \\
(\mathrm{N}=36)\end{array}$} & \multicolumn{3}{c}{$\begin{array}{c}\text { Double confederate treatment } \\
(\mathrm{N}=37)\end{array}$} \\
\cline { 2 - 7 } & Mean & Median & Mean & Median & Mean & Median & $\begin{array}{c}\text { Standard } \\
\text { deviation }\end{array}$ & Zero bids \\
\hline Round 1 & $\$ 1.04$ & $\$ 1.00$ & $\$ 1.26$ & $\$ 0.72$ & $\$ 1.60$ & $\$ 1.00$ & $\$ 2.00$ & $27.0 \%$ \\
Round 2 & $\$ 1.20$ & $\$ 1.00$ & $\$ 1.68$ & $\$ 1.13$ & $\$ 1.70$ & $\$ 1.00$ & $\$ 2.03$ & $27.0 \%$ \\
Round 3 & 1.34 & $\$ 1.25$ & $\$ 2.04$ & $\$ 1.25$ & $\$ 1.72$ & $\$ 1.00$ & $\$ 2.01$ & $27.0 \%$ \\
Round 4 & $\$ 1.49$ & $\$ 1.31$ & $\$ 2.07$ & $\$ 1.00$ & $\$ 2.04$ & $\$ 1.00$ & $\$ 2.42$ & $27.0 \%$ \\
Round 5 & $\$ 1.50$ & $\$ 1.29$ & $\$ 2.40$ & $\$ 1.00$ & $\$ 1.80$ & $\$ 1.00$ & $\$ 2.08$ & $27.0 \%$ \\
Round 6 & $\$ 1.46$ & $\$ 1.27$ & $\$ 2.04$ & $\$ 1.00$ & $\$ 1.84$ & $\$ 1.00$ & $\$ 2.13$ & $24.3 \%$ \\
Round 7 & $\$ 1.49$ & $\$ 1.25$ & $\$ 2.39$ & $\$ 1.00$ & $\$ 2.04$ & $\$ 1.75$ & $\$ 2.28$ & $29.7 \%$ \\
Round 8 & $\$ 1.55$ & $\$ 1.28$ & $\$ 2.56$ & $\$ 1.07$ & $\$ 1.64$ & $\$ 1.00$ & $\$ 1.71$ & $35.1 \%$ \\
Round 9 & $\$ 1.48$ & $\$ 1.23$ & $\$ 2.65$ & $\$ 1.00$ & $\$ 1.97$ & $\$ 1.09$ & $\$ 2.20$ & $32.4 \%$ \\
Round 10 & $\$ 1.45$ & $\$ 1.22$ & $\$ 2.71$ & $\$ 1.10$ & $\$ 2.02$ & $\$ 1.06$ & $\$ 2.26$ & $11.0 \%$ \\
\hline
\end{tabular}


Table 9. Summary Statistics for Coffee Mug Bids in Experiment 3

\section{Round $1 \quad$ Round $9 \quad$ Difference}

Control treatment $(\mathrm{N}=28)$

$\begin{array}{lrrr}\text { Mean } & \$ 1.04 & \$ 1.48 & \$ 0.44 \\ \text { Median } & \$ 1.00 & \$ 1.23 & \$ 0.23\end{array}$

Confederate treatment $(\mathrm{N}=36)$

$\begin{array}{lrrr}\text { Mean } & \$ 1.26 & \$ 2.65 & \$ 1.39 \\ \text { Median } & \$ 0.72 & \$ 1.00 & \$ 0.28\end{array}$

Double confederate treatment $(\mathrm{N}=37)$
Mean
$\$ 1.60$
$\$ 1.97$
$\$ 0.37^{\dagger}$
Median
$\$ 1.00$
$\$ 1.09$
$\$ 0.09$

$\dagger$ Statistically different across control and confederate treatments at the 0.02 level $(t=2.03)$. No significant difference across control and double confederate treatments $(t=0.28)$. 
Table 10. Random-Effects Estimation Results for Coffee Mug Bids in Experiment 3 $(\mathrm{N}=\mathbf{6 5 0})$

\begin{tabular}{ccc}
\hline Variable & $(1)$ & $(2)$ \\
& & \\
\hline Constant & $1.451^{* *}$ & $1.172^{* *}$ \\
Trend & $(0.000)^{\mathrm{a}}$ & $(0.001)$ \\
Male & $0.037^{*}$ & $0.037^{*}$ \\
& $(0.016)$ & $(0.016)$ \\
Income & - & 0.431 \\
GPA & - & $(0.304)$ \\
Trend $\times$ Confederate & - & -0.003 \\
& & $(0.979)$ \\
Trend $\times$ Confederate $\times$ Male & -0.001 & 0.211 \\
Trend $\times$ Confederate $\times$ Income & $(0.952)$ & $0.715)$ \\
& - & 0.030 \\
Trend $\times$ Confederate $\times$ GPA & - & -0.048 \\
$\mathrm{R}^{2}$ & - & $(0.105)$ \\
& & -0.002 \\
& 0.003 & $(0.814)$ \\
& & -0.040 \\
& & $(0.256)$ \\
& & 0.011
\end{tabular}

${ }^{\mathrm{a}} p$ values in parentheses.

* Significant at the 0.05 level

** Significant at the 0.01 level. 


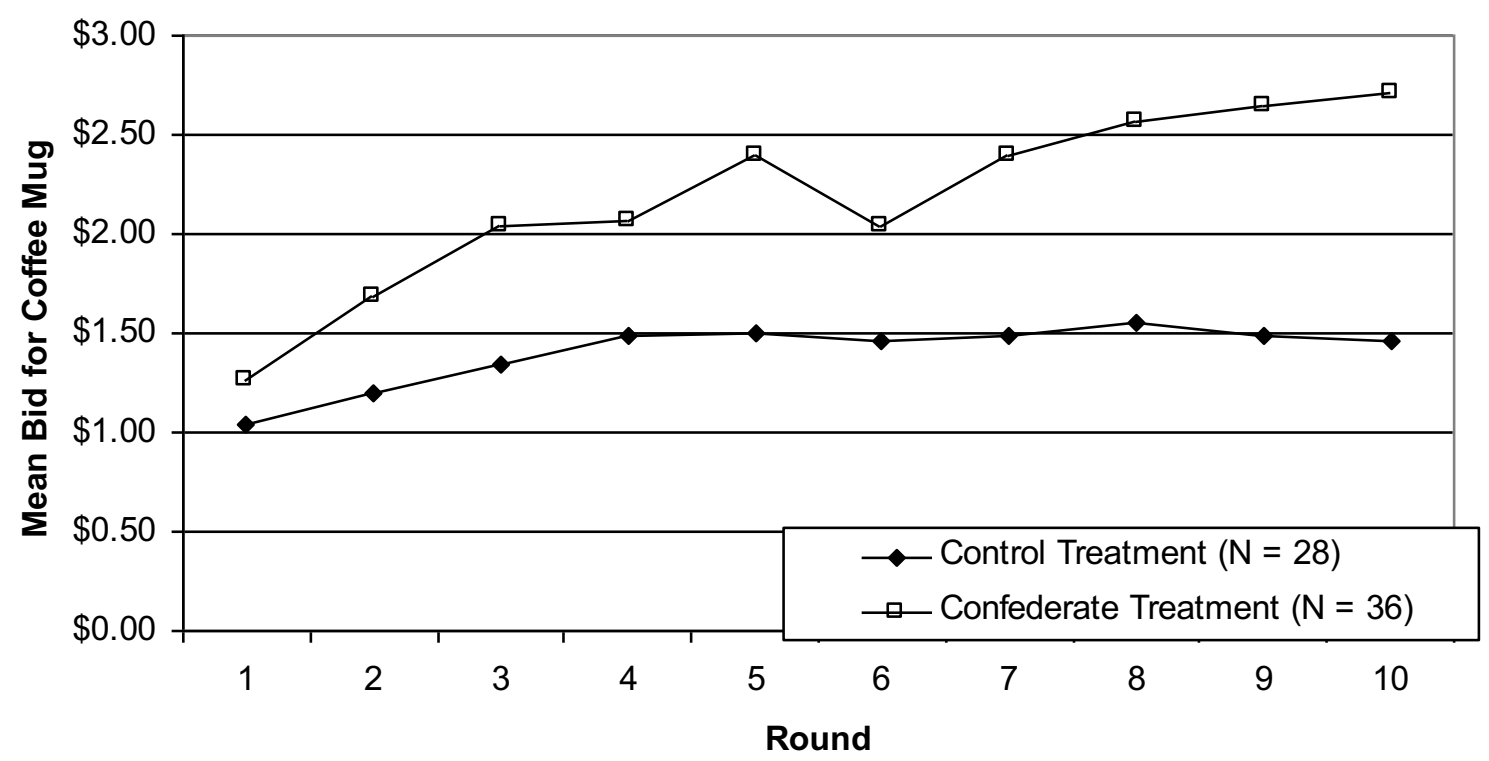

Figure 1. Mean bids for the coffee mug across rounds in experiment 1 


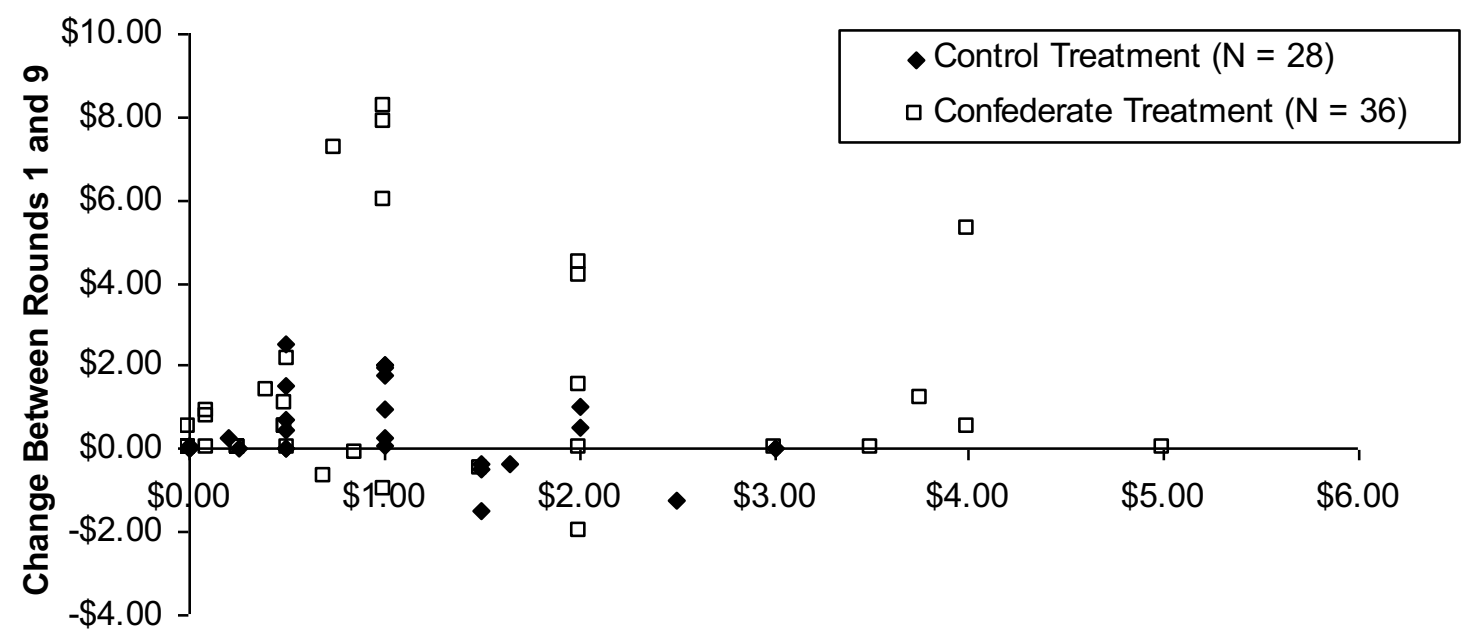

Round 1 Bid

Figure 2. Initial coffee mug bids versus increase across rounds in experiment 1 


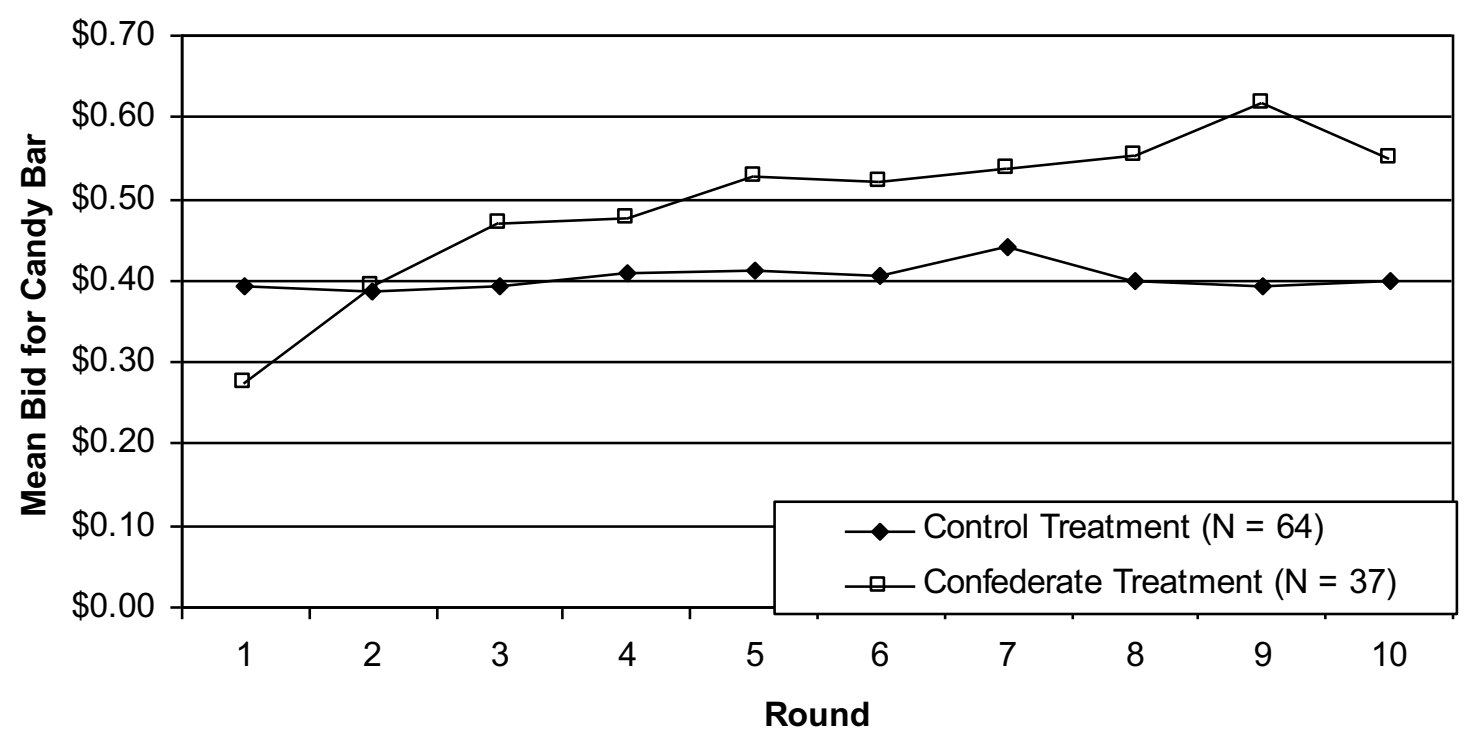

Figure 3. Mean bids for the candy bar across rounds in experiment 2 


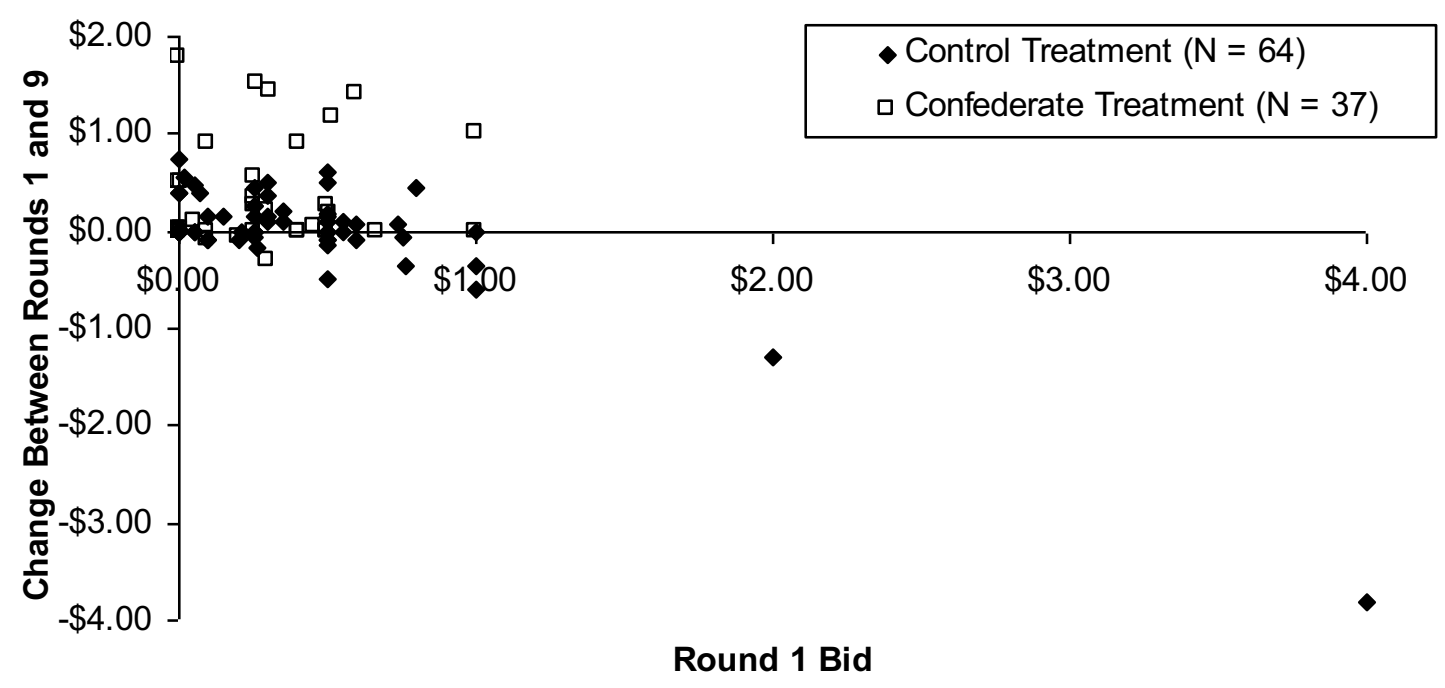

Figure 4. Initial candy bar bids versus increase across rounds in experiment 2 


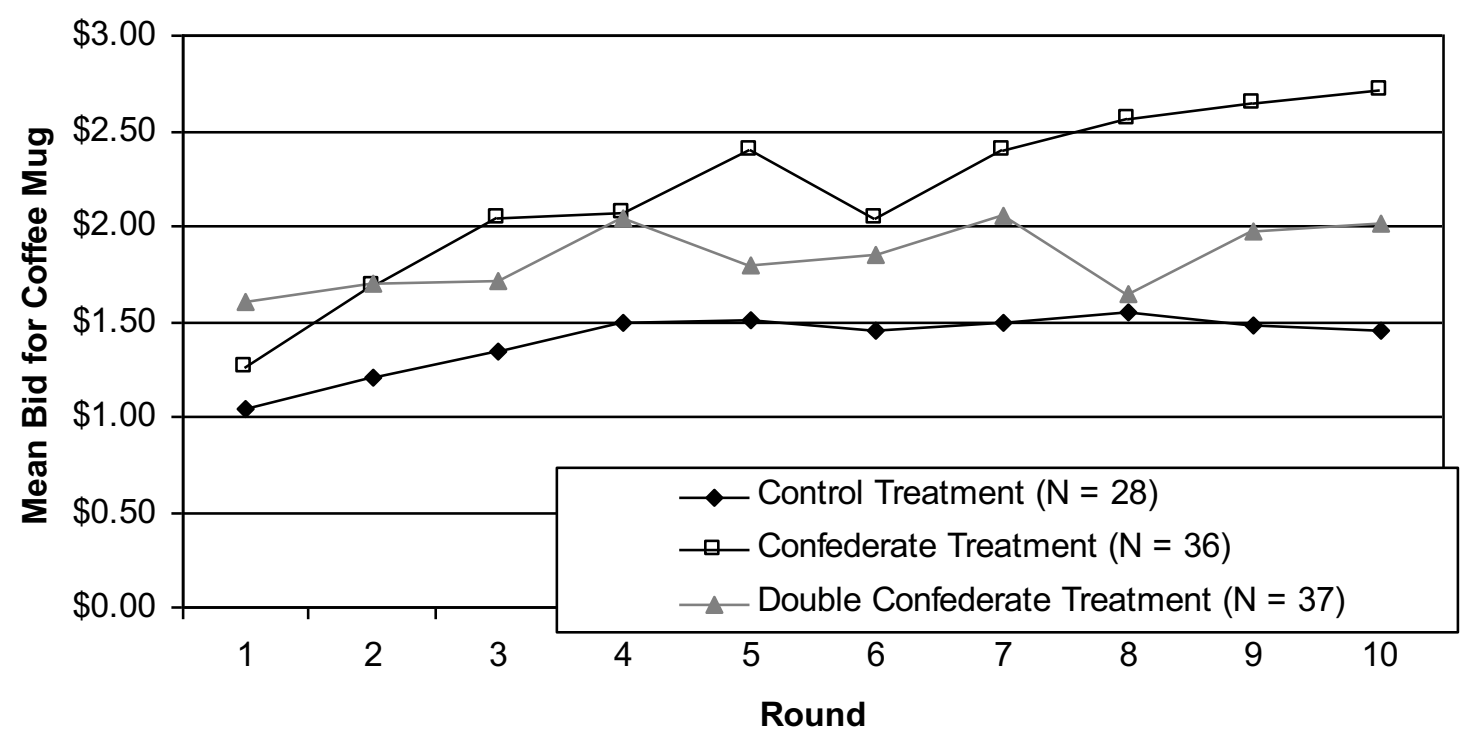

Figure 5. Mean bids for the coffee mug across rounds in experiment 3, including the bidders in the rounds with the confederate bidders for both the coffee mug and the candy bar 


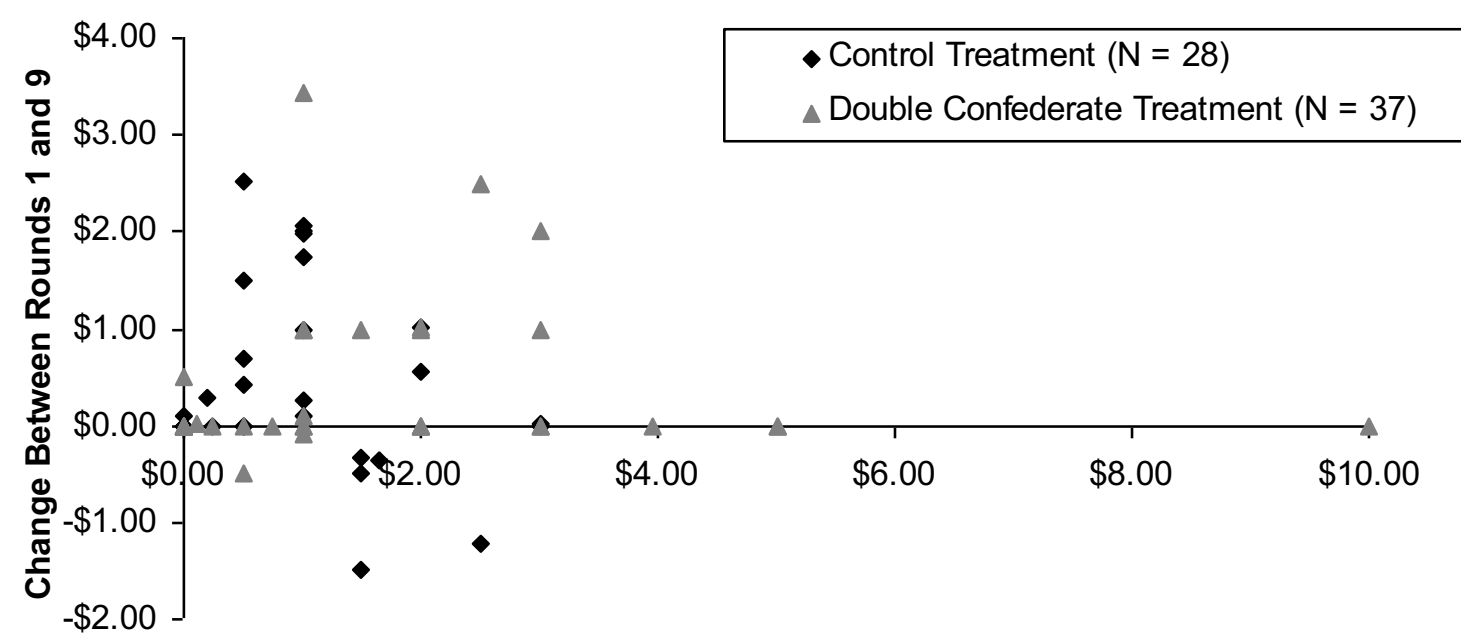

Round 1 Bid

Figure 6. Initial coffee mug bids versus increase across rounds in experiment 3 